\title{
Effects of age and lesions of the nucleus basalis on contextual fear conditioning
}

\author{
JAMES D. STOEHR and GARY L. WENK \\ University of Arizona, Tucson, Arizona
}

\begin{abstract}
We examined the effects of excitatory amino acid (EAA) lesions of the nucleus basalis magnocellularis (NBM) in young (3-month-old), adult (9-month-old), and aged (24-month-old) rats on the expression of conditioned freezing to an environmental context and to a discrete conditioned stimulus (CS; tone) in a Pavlovian fear-conditioning task. Lesions caused by injections of NMDA resulted in reductions in the levels of conditioned freezing to the context (Skinner box) in each age group, while freezing levels displayed during the presentation of the tone were unaffected. In addition, a significant decline in the levels of freezing to context, but not to the tone, was found in the 24-month-old age group. These results suggest that the nucleus basalis plays a role in the expression of conditioned fear to environmen: tal context and in the behavioral changes associated with the normal aging process, and that the vulnerability of these cells to excitotoxic damage, and the resulting behavioral deficit, increases with age.
\end{abstract}

A complex pattern of degenerative changes occurs within the brain during normal aging and in Alzheimer's disease (AD; Whitehouse, Struble, Hedreen, Clark, \& Price, 1985). Such changes include, but are not limited to, the loss of specific neural systems that underlie the normal mechanisms associated with learning and attention. The loss of acetylcholine neurons within the nucleus basalis of Meynert in the basal forebrain may be responsible for some of the cognitive impairments associated both with aging (Lowes-Hummel, Gertz, Ferszt, \& Cervos-Navarro, 1989) and with AD in humans (Bartus, Dean, Beer, \& Lippa, 1982; Coyle, Price, \& DeLong, 1983). The mechanisms that underlie these normal agerelated and pathological changes may involve the activation of excitatory amino acid (EAA) receptors by endogenous amino acid neurotransmitters in specific neural systems (Faden, Demediuk, Panter, \& Vink, 1989; Greenamyre \& Young, 1989; Olney, 1989). The nucleus basalis magnocellularis (NBM) is a region in the basal forebrain of rats that is analogous to the nucleus basalis of Meynert in humans in that it contains a population of large cholinergic neurons that project to the neocortical mantle (Rye, Wainer, Mesulam, Mufson, \& Saper, 1984).

Behavioral deficits associated with experimental lesions caused by injections of EAAs into the NBM have been demonstrated in studies utilizing punishment such as passive avoidance tasks (Bartus et al., 1985; Miyamoto, Shintani, Nagaoka, \& Nagawa, 1985). Performance decrements in these tasks following bilateral and unilateral excitotoxic lesions of the NBM have been interpreted as being a result of impairments in learning

Correspondence should be addressed to J. D. Stoehr, Arizona Research Laboratories, Division of Neural Systems, Memory and Aging, 384 Life Sciences North Building, Tucson, AZ 85724 (e-mail: jims@) nsma.arizona.edu). and memory (Bartus et al., 1985; Flicker, Dean, Watkins, Fisher, \& Bartus, 1983; Miyamoto et al., 1985). However, only a few of these tasks employed measurements of spontaneous motor activity as a result of excitotoxic lesions. Hyperactivity associated with basal forebrain lesions may underlie the retention impairments in avoidance tasks. Therefore, avoidance tasks used to demonstrate behavioral impairments following NBM lesions must utilize quantitative measurements of hyperactivity in a novel environment.

In addition to the behavioral effects of NBM lesions, several cognitive changes take place in the normal aging process. Decrements in behavioral tasks associated with age have been correlated with age-related alterations in certain brain structures involved with learning and memory (Barnes, 1979; see Barnes, 1994). As a result, impairments in behavioral tasks in aged animals have been claimed to be due to the loss of cells in structures associated with learning and memory such as the limbic system (Meany, Aitken, Bhatnagar, \& Sapolsky, 1991). However, few studies have used behavioral tasks involving any form of punishment other than in avoidance to evaluate the cognitive decrements associated with normal aging and NBM lesions.

In the present experiments, the effects of NMDA lesions of the NBM in young (3-month-old), adult (9-monthold), and aged (24-month-old) rats were examined in the expression of conditioned freezing to environmental context and to a discrete conditioned stimulus presented in a novel environment in the conditioned-freezing task.

\section{METHOD}

\section{Subjects}

Thirty-four male Fisher 344 rats, either 3 months old $(n=10)$, 9 months old $(n=10)$, or 24 months old $(n=10)$ at the start of the experiment, were used in the present study. All rats were given routine weekly health checks and were doubly housed in a room 
with a constant temperature $\left(24^{\circ} \mathrm{C}\right)$, humidity $(50 \%)$, and a 12 -h light:dark cycle with lights off at 10 a.m. Experiments were conducted during the dark cycle. Food and water were provided ad lib following surgery and during the experimental period.

\section{Surgery \\ Standard procedures were used for the surgery (Wenk, Markow- ska, \& Olton, 1989). Each rat was injected with atropine $(5 \mathrm{mg} / \mathrm{kg}$, i.p.), anesthetized with sodium pentobarbital $(50 \mathrm{mg} / \mathrm{kg}$, i.p.), and secured in a stereotaxic apparatus (Kopf). The bilateral lesion co- ordinates were as follows: $0.6 \mathrm{~mm}$ posterior to bregma; $2.8 \mathrm{~mm}$ lat- eral to midline; and $6.8 \mathrm{~mm}$ below the dorsal surface of the cortex. The neurotoxin NMDA $(0.03 \mathrm{M}, \mathrm{pH} 7.4$ in phosphate-buffered saline) was injected ( $0.5 \mu \mathrm{l}$ per site) over a 5 -min period to limit diffusion. The control groups had the injection cannula lowered to the same coordinates used for the lesions; however, no injections were made. Each rat was allowed 10 days in which to recover from surgery and was then handled for 2 min each day over a 4-5-day period prior to training.}

\section{Fear-Conditioning Apparatus}

The apparatus and procedure used in the conditioned-freezing paradigm were fashioned after those described by Fanselow (1980). The shock chamber $(23.5 \mathrm{~cm}$ high $\times 29 \mathrm{~cm}$ wide $\times 19.5 \mathrm{~cm}$ deep $)$ was placed on a platform $20 \mathrm{~cm}$ above a table located in a soundattenuated room. A video camera was stationed $1.5 \mathrm{~m}$ from the chamber and recorded each training and testing session for later analyses. The floor of the chamber comprised 18 stainless steel rods, each $2.5 \mathrm{~mm}$ in diam, and spaced $1.25 \mathrm{~cm}$ apart. The rods were connected to a shock generator/scrambler (Lafayette Instruments). The chamber was cleaned with a $5 \%$ ammonium hydroxide solution prior to, and immediately after, each training session. In an adjoining room, experimenters observed the behavior of each rat through a $1.5 \times 1.5 \mathrm{~m}$ one-way mirror in the front wall of the sound-attenuated room.

\section{Training and Testing}

On the day following handling, each rat was placed in the shock chamber for training. After an exploration period of $3 \mathrm{~min}$, àn auditory stimulus ( $30 \mathrm{sec}, 85 \mathrm{~dB}$ ) was delivered; this coterminated with a brief footshock $(1 \mathrm{sec}, 0.8 \mathrm{~mA})$. This procedure was repeated once more, for a total of two conditioning trials. Immediately following the second shock, each rat was removed from the chamber and returned to its home cage.

Contextual conditioning was assessed $24 \mathrm{~h}$ later, when each rat was placed in the same chamber but no shock was administered. Behavior was scored every $2 \mathrm{sec}$ for $8 \mathrm{~min}$ by two experimenters, blind to treatment conditions, as either freezing (the lack of all visible body movements except for that necessitated by respiration) or activity (all other behaviors, including rearing and grooming). Behavioral scores were also used to calculate the percentage of interrater reliability for observations between experimenters.

Conditioning to the auditory stimulus was assessed the following day. Each rat was placed in a Plexiglas cylinder $(32 \times 32 \mathrm{~cm})$ mounted on a stainless steel table in a different room from that in which the original conditioning had occurred. The cylinder and table were cleaned with a $5 \%$ acetic acid solution before and after each subject. After an exploration period of $3 \mathrm{~min}$ (pre-conditioned stimulus [CS] period), the auditory stimulus was presented for $5 \mathrm{~min}$ (CS period). The behavior of each rat was recorded with a video camera and observed by the experimenters with a monitor in an adjoining room.

\section{Biochemistry}

After behavioral testing was completed, each rat was anesthetized with metophane and sacrificed by decapitation. The brain was removed and rapidly dissected on ice. A caronal slab of the brain was prepared using a brain matrix (Model RBM-4000C, Activational Systems, Warren, MI). The coronal slab was obtained by making a rostral cut just anterior to the optic chiasm and a second cut $2 \mathrm{~mm}$ caudal to the first. A small section of the caudate nucleus (approximately $20 \mathrm{mg}$ ) was taken from this slab. Tissue samples were also taken bilaterally from the frontolateral sensorimotor and parietal-occipital cortices, the entire hippocampus, and the olfactory bulbs, and stored at $-70^{\circ} \mathrm{C}$.

Choline acetyltransferase (ChAT) activity has been demonstrated to be specific for cholinergic cells. The anatomical extent of each lesion within the NBM, but not its specificity, can be indirectly estimated by the degree to which each toxin decreased the level of ChAT activity throughout the neocortex and subcortical structures (Wenk, Cribbs, \& McCall, 1984; Wenk et al., 1989; Wenk, Harrington, Tucker, Rance, \& Walker, 1992). ChAT activity was measured by the formation of $[14 \mathrm{C}]$-acetylcholine from [1-14C]-acetyl-coenzyme-A and choline (Fonnum, 1969). Protein content of the homogenate was also assayed by the method of Lowry, Rosenbrough, Farr, and Randall, 1951.

\section{RESULTS}

\section{Behavior}

A two-way analysis of variance (ANOVA; age $\times$ lesion) of the freezing levels to context (see Figure 1) showed main effects of age $[F(2,27)=3.77, p<.05]$ and lesion $[F(2,27)=7.04, p<.05]$. Post hoc Newman-Keuls comparisons showed that the 24-month-old control rats froze significantly less than the 3-month-old controls, that the 24-month-old lesioned rats froze less than the 9month-old lesioned rats, and that the 3-month-old lesioned rats froze less than the 3-month-old controls $(p<$ .05 ). No other significant effect of age group or lesion, nor any interaction between the two in the levels of freezing to context, was found.

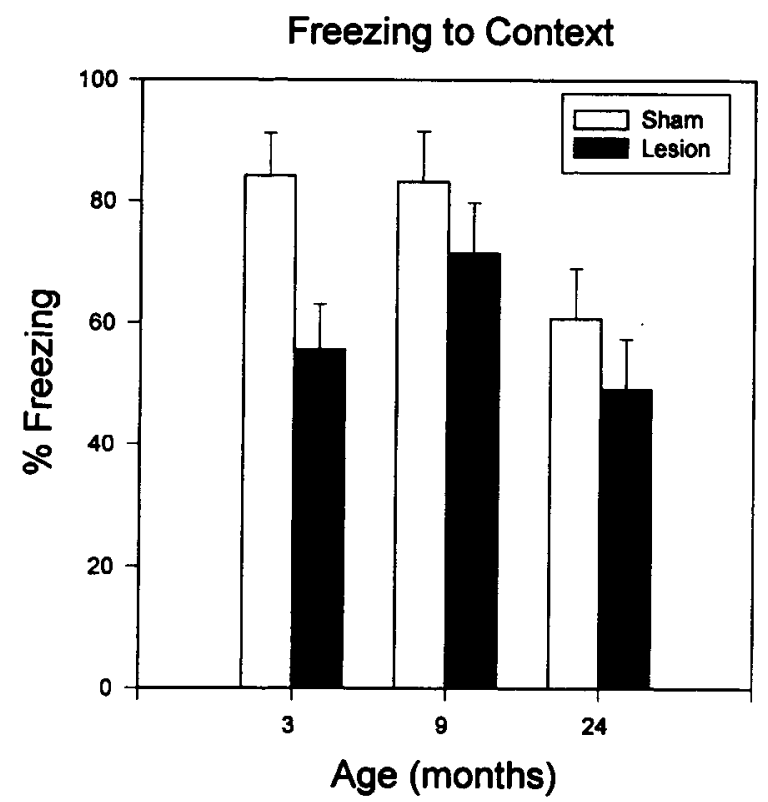

Figure 1. Freezing-level percentages to environmental context as a function of age and lesion during an 8-min test. Bars represent the standard errors. 
A two-way ANOVA (age group $\times$ lesion) of the freezing levels during the pre-CS condition (see Figure 2) showed a main effect of lesion $[F(2,27)=4.79, p<.05]$, no main effect of age group $[F(2,27)=0.31, p=.74]$, and no significant interaction $[F(4,27)=0.05, p=.95]$. Post hoc Newman-Keuls comparisons revealed a significant $(p<.05)$ difference between the 9-month-old controls and the NMDA-lesioned rats.

A two-way ANOVA (age group $\times$ lesion) of the freezing levels during the presentation of the CS (see Figure 3 ) showed no main effect of lesion $[F(2,26)=2.28, p=$ $.143]$, no main effect of age group $[F(2,26)=2.46, p=$ $.105]$, and no significant interaction $[F(4,26)=0.34$, $p=.717]$. Data on freezing levels from one 3-month-old rat were excluded from the analysis in the CS condition because the animal escaped from the chamber during testing. Interrater reliability averaged $88.4 \%$ for scoring of all of the behavioral data.

\section{Biochemistry}

A two-way ANOVA (age $\times$ lesion) of the ChAT data obtained from the anterior sensorimotor neocortex showed a significant decline due to lesion $[F(2,27)=18.95, p<$ $.0005]$ but not due to age group $[F(2,27)=0.065, p=$ $.938]$, and no significant interaction $[F(4,27)=0.53$, $p=.591]$. Post hoc Newman-Keuls comparisons showed that injections of NMDA significantly de-creased neocortical ChAT activity $(p<.05)$, as compared with control levels, across all three age groups. Three-month-old lesioned rats had a $17.7 \%$ decline in ChAT levels in the anterior cortex as compared with controls, 9-month-old lesioned rats had a 7.6\% decline, and 24-month-old lesioned rats had an $11.8 \%$ drop in ChAT levels.

A two-way ANOVA (age $\times$ lesion) of the ChAT data obtained from the posterior parietal/occipital neocortex

\section{Freezing to Pre - CS}

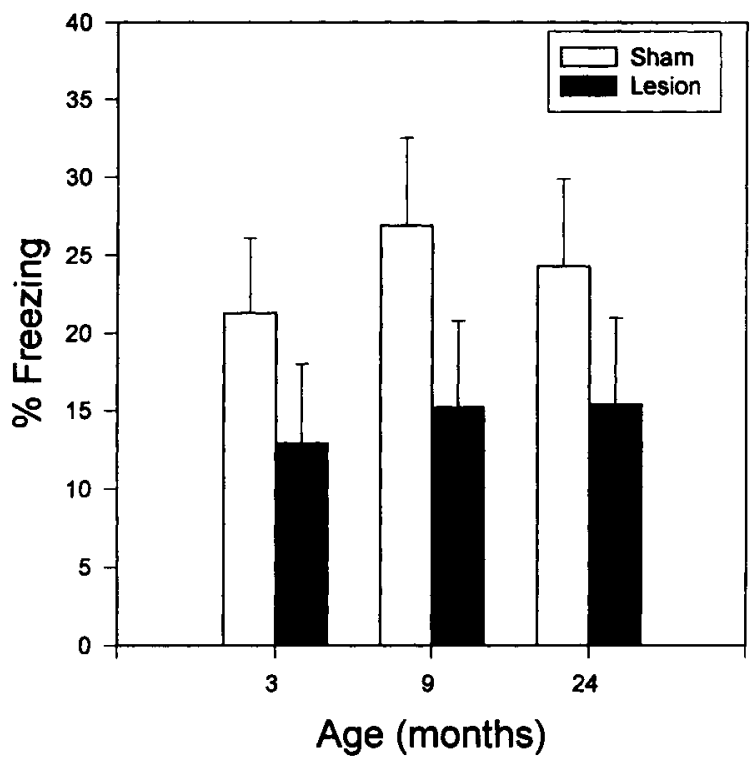

Figure 2. Freezing-level percentages to a novel context $3 \mathrm{~min}$ prior to the presentation of the discrete CS (tone).

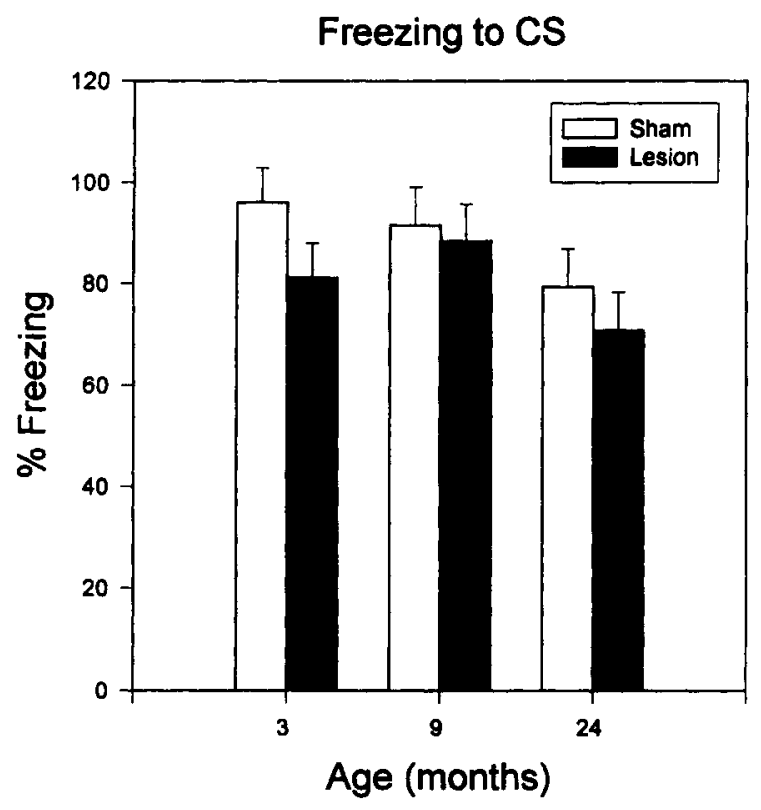

Figure 3. Freezing-level percentages observed during the 5-min auditory cue test.

showed no significant decline due to the lesion $[F(2,27)=$ $0.003, p=.955]$ nor to age group $[F(2,27)=0.899, p=$ $.418]$, and no significant interaction $[F(4,27)=0.678$, $p=.515]$.

ANOVAs of the ChAT activity within the caudate nucleus, hippocampus, and olfactory bulbs showed no significant overall main effect of groups (i.e., neither age nor lesion affected ChAT activity in these brain regions). In addition, no significant correlations between regional levels of ChAT activity and freezing-level percentages in each behavioral test were found $(p>.05$, all comparisons).

\section{DISCUSSION}

The results of the present study are the first to demonstrate behavioral deficits in contextual fear conditioning associated with normal aging in the rat. The fact that significant effects that were due to the age of the animals were realized suggests that the normal decline in cognitive abilities associated with aging in the rat (Barnes, 1994 ) is sufficient to impair the acquisition or expression of conditioned fear to contextual stimuli in the present paradigm.

The deficits found in the recent study, however, are dependent upon the presentation of the specific conditioned stimuli used in the task. During the pre-CS period, the amount of unconditioned freezing displayed was sensitive to the presence of the lesion but not to the age of the rat. This important result suggests that the impairments in freezing to the context in the lesioned rats may be directly related to the level of motor activity, but not conditioned immobility, displayed in certain environments. Several studies have demonstrated hyperactivity in open- 
field arenas in young rats with excitotoxic NBM lesions (Dubois, Mayo, Agid, LeMoal, \& Simon, 1985; Haroutunian, Kanof, \& Davis, 1985; Lerer, Warner, \& Freidman, 1986; Whishaw, O'Connor, \& Dunnett, 1985). Therefore, the possibility exists that the lesion effects found during context testing may be due to nonspecific damage to neighboring nuclei in the basal forebrain that control motor inhibition, such as the globus pallidus and putamen. This result may hinder interpretations of the effects of NBM lesions upon avoidance behavior (Flicker et al., 1983; Bartus et al., 1985; Miyamoto et al., 1985). The possibility exists that the attenuated latencies in passive avoidance tasks demonstrated by lesioned animals may not be due to the direct impact of NBM cell loss on acquisition, consolidation, or retrieval of information, but may be more related to the enhanced mobility and hyperactivity produced by basal forebrain lesions.

The lack of significant effects of age or lesion upon freezing to the presentation of the tone may reflect the saliency of the conditioned stimulus (i.e., the presentation of a very discrete and salient tone may trigger more emotional reactivity than the presentation of the original context). Several authors have suggested that conditioning to discrete visual or auditory stimuli illicits robust conditioned and unconditioned responses (Fanselow, 1993; Rudy \& Morledge, 1994). On the other hand, the neural mechanisms that underlie acquisition and expression of conditioned fear to auditory stimuli may remain unaffected by NBM lesions or aging. For example, structures involved in auditory fear conditioning (such as the medial geniculate, amygdaloid nuclei, and autonomic brain-stem areas; Davis, 1992; LeDoux, 1992) are well preserved in the aged rat and in rats with excitotoxic NBM lesions (Beninger, Jhamandas, Boegman, \& ElDefrawy, 1986). Therefore, the behavioral deficiencies associated with NBM lesions or normal aging in the rat (Fischer, Chen, Gage, \& Bjordlund, 1991) may be too subtle to play a significant role in the acquisition or retrieval of the auditory CS.

There is a growing body of evidence that the hippocampus is involved in the acquisition of complex contextual information during fear conditioning, whereas the amygdala is involved with both contextual and discrete CS processing (Kim \& Fanselow, 1992; Phillips \& LeDoux, 1992; see LeDoux, 1992). In the present study, cholinergic markers within the hippocampus were unaffected by age or NMDA injections into the NBM. Likewise, conditioning to the discrete CS was unaffected by age or lesion. Therefore, it is possible that the deficits found in the present study are more related to subtle cognitive deficits, such as those in attention or vigilance, that take place during aging or following small NBM lesions (McGaughy, Turchi, \& Sarter, 1994). In support of this notion, recent evidence supports a role of the frontal cortical areas in the extinction of contextual fear conditioning (Morgan, Romanski, \& LeDoux, 1993). Future research should attempt to identify the specific involvement of the basal forebrain and cortical targets in the processing of complex contextual stimuli during fear-related events.
The effects of injections of NMDA into the NBM on behavioral performance may be related to the overall cell loss within the NBM. However, this cell loss may not necessarily be due to the preferential destruction of cholinergic cells. A recent study has shown that specific loss of cholinergic cells within the NBM did not result in deficits in contextual freezing during a passive avoidance task (Wenk, Stoehr, Quintana, Mobley, \& Wiley, 1994). Therefore, the loss of noncholinergic cells within the basal forebrain region may underlie the behavioral deficits resulting from excitotoxic lesions of the NBM in fear-conditioning and avoidance paradigms. The lack of a correlation between cholinergic markers in the frontal cortex and contextual freezing in the present study supports this notion. These results suggest the possibility that an increased vulnerability in a noncholinergic NBM neural system may underlie the behavioral impairment of aged rats observed in the present study. Therefore, there may exist a threshold in the number of NBM cells, both cholinergic and noncholinergic, that must be lost during the normal aging process in order to impair performance in fear-conditioning tasks. When the number of NBM cells falls below that threshold, due to advanced aging or exposure to EAAs, then performance of these neural systems will be impaired.

\section{REFERENCES}

BARnes, C. A. (1979). Memory deficits associated with senescence: A neurophysiological and behavioral study in the rat. Journal of Comparative \& Physiological Psychology, 93, 74-104.

BARNES, C. A. (1994). Normal aging: Regionally specific changes in hippocampal synaptic transmission. Trends in Neurosciences, 17, 13-18.

Bartus, R. T., Dean, R. L., Beer, B., \& Lippa, A. S. (1982, July). The cholinergic hypothesis of geriatric memory dysfunction. Science, 217, 408-417.

Bartus, R. T., Flicker, C., Dean, R. L., Pontecorvo, M., Figueiredo, J. C., \& Fisher, S. K. (1985). Selective memory loss following nucleus basalis lesions: Long term behavioral recovery despite persistent cholinergic deficiencies. Pharmacology, Biochemistry \& Behavior, 23, 125-135.

Beninger, R. J., Jhamandas, K., Boegman, R. J., \& El-Defrawy, S. R. (1986). Effects of scopolamine and unilateral lesions of the basal forebrain on T-maze spatial discrimination and alternation in rats. Pharmacology, Biochemistry \& Behavior, 24, 1353-1360.

Coyle, J. T., Price, D. L., \& Delong, M. R. (1983, March). Alzheimer's disease: A disorder of cortical cholinergic innervation. Science, 219, 1184-1190.

DAvis, M. (1992). The role of the amygdala in conditioned fear. In J. P. Aggleton (Ed.), The amygdala: Neurobiological aspects of emotion, memory, and mental dysfunction (pp. 255-305). New York: WileyLiss.

Dubois, B., Mayo, W., Agid, Y., LeMoal, M., \& Simon, H. (1985). Profound disturbances of spontaneous and learned behaviors following lesions of the nucleus basalis magnocellularis in the rat. Brain Research, 338, 249-258.

Faden, A. L., Demediuk, P., PANTer, S. S., \& Vink, R. (1989, May). The role of excitatory amino acids and NMDA receptors in traumatic brain injury. Science, 244, 798-800.

FANSELOW, M. S. (1980). Conditional and unconditional components of post-shock freezing. Pavlovian Journal of Biological Science, 15, 177-182.

FANSELOW, M. S. (1993). Associations and memories: The role of NMDA receptors and long-term potentiation. Current Directions in Psychological Science, 2, 152-156. 
Fischer, W., Chen, K. S., Gage, F. H., \& Bjordlund, A. (1991). Progressive decline in spatial learning and integrity of forebrain cholinergic neurons in rats during aging. Neurobiology of Aging, 13, 9-23.

Flicker, C., Dean, R., Watkins, D. L., Fisher, S. K., \& Bartus, R. T. (1983). Behavioral and neurochemical effect following neurotoxic lesions of a major cholinergic input to the cerebral cortex in the rat. Pharmacology, Biochemistry \& Behavior, 18, 973-981.

FonNUM, F. (1969). Radiochemical microassays for the determination of choline acetyltransferase and acetylcholinesterase activities. Journal of Biochemistry, 115, 465-472.

Greenamyre, J. T., \& Young, A. B. (1989). Excitatory amino acids and Alzheimer's disease. Neurobiology of Aging, 10, 593-602.

Haroutunian, V., Kanof, P., \& Davis, M. D. (1985). Pharmacological alleviation of cholingergic induced memory deficits in rats. Life Sciences, 37, 945-952.

Kim, J. J., \& FanSELow, M. S. (1992, May). Modality specific retrograde amnesia of fear following hippocampal lesions. Science, 256, 675-677.

LeDoux, J. E. (1992). Emotion and the amygdala. In J. P. Aggleton (Ed.), The amygdala: Neurobiological aspects of emotion, memory, and mental dysfunction (pp. 229-254). New York: Wiley-Liss.

LeRER, B., WarneR, J., \& Freidman, E. (1986). Cortical cholinergic impairment and behavioral deficits produced by kainic acid lesions of rat magnocellular basal forebrain. Behavioral Neuroscience, 99, $661-667$

Lowes-Hummel, P., Gertz, H.-J., Ferszt, R., \& Cervos-NavarRo, J. (1989). The basal nucleus of Meynert revised: The nerve cell number decreases with age. Archives of Gerontology \& Geriatrics, 8, 21-27.

Lowry, O. H., Rosenbrough, N. J., FaRr., A. L., \& Randall, R. J. (1951). Protein measurement with folin phenol reagent. Journal of Biological Chemistry, 193, 265-275.

McGaughy, J., TurChi, J., \& Sarter, M. (1994). Crossmodal divided attention in rats: Effects of chlordiazepoxide and scopolamine. Psy. chopharmacology, 115, 213-220.

Meany, M. J., Aitken, D. H., Bhatnagar, S., \& Sapolsky, R. M. (1991). Postnatal handling attenuates certain neuroendocrine, anatomical, and cognitive dysfunctions associated with aging in female rats. Neurobiology of Aging, 12, 31-38.

Miyamoto, M., Shintani, M., Nagaoka, A., \& Nagawa, Y. (1985). Lesioning of the rat basal forebrain leads to memory impairments in passive and active avoidance tasks. Brain Research, 328, 97-104

MoRgan, M. A., RomANSKI, L. M., \& LeDoux, J. E. (1993). Extinction of emotional learning: Contribution of the medial prefrontal cortex. Neuroscience Letters, 163, 109-113.
OLNEY, J. W. (1989). Excitatory amino acids and neuropsychiatric disorders. Biological Psychiatry, 26, 505-525.

Phillips, R. G., \& LeDoux, J. E. (1992). Differential contribution of amygdala and hippocampus to cued and contextual fear conditioning. Behavioral Neuroscience, 106, 274-285.

RUDY, J. W., \& MORLEDGE, P. (1994). The ontogeny of contextual fear conditioning: Implications for consolidation, infantile amnesia, and hippocampal system function. Behavioral Neuroscience, 108, 227234.

Rye, D. B., Wainer, B. H., Mesulam, M.-M., Mufson, E. J., \& SaPer, C. B. (1984). Cortical projections arising from the basal forebrain: A study of cholinergic and noncholinergic components employing combined retrograde tracing and immunohistochemical localization of choline acetyltransferase. Neuroscience, 13, 627-643.

WENK, G. L., CriBBS, B., \& MCCALL, L. (1984). Nucleus basalis magnocellularis: Optimal coordinates for selective reduction of choline acetyltransferase in frontal neocortex by ibotenic acid injections. Experimental Brain Research, 56, 335-340.

Wenk, G. L., Harrington, C. A., Tucker, D. A., Rance, N. E., \& WALKER, L. C. (1992). Basal forebrain neurons and memory: A biochemical, histological and behavioral study of differential vulnerability to ibotenate and quisqualate. Behavioral Neuroscience, 106, 909-923.

Wenk, G. L., Markowska, A., \& Olton, D. S. (1989). Basal forebrain lesions and memory: Alterations in neurotensin, not acetylcholine, may cause amnesia. Behavioral Neuroscience, 103, 765-769.

WenK, G. L., Stoehr, J. D., Quintana, G., Mobley, S., \& Wiley, R. G. (1994). Behavioral, biochemical, histological, and electrophysiological effects of 192 IgG-saporin injections into the basal forebrain of rats. Journal of Neuroscience, 14, 5986-5995.

Whishaw, I. Q., O'ConNOR, W. T., \& DUNNETT, S. B. (1985). Disruption of central cholinergic systems in the rat by basal forebrain lesions or atropine: Effects on feeding, sensorimotor behavior, locomotor activity and spatial navigation. Behavioral Brain Research, 17, 103-115

Whitehouse, P. J., Struble, R. G., Hedreen, J. C., Clark, A. W., \& Price, D. L. (1985). Alzheimer's disease and related dementias: Selective involvement of specific neuronal systems. In J. C. Blass (Ed.), Critical reviews in clinical neurobiology (pp. 319-339). New York: CRC.

(Manuscript received March 2, 1995 revision accepted for publication May 19, 1995.) 